\section{6-month treatment with a low- glycaemic diet was better than a high- fibre diet for glycaemic control in type 2 diabetes}

\section{STUDY DESIGN}

Design: randomised controlled trial.

Allocation: unclear. *

Blinding: blinded (technical staff and statistician for the preliminary assessment of glycated haemoglobin $\left[\mathrm{HbA}_{1 \mathrm{c}}\right]$ concentrations). *

\section{STUDY QUESTION}

Setting: St Michael's Hospital, Toronto, Ontario, Canada. Patients: 210 patients (mean age $60 \mathrm{y}, 61 \%$ men) with type 2 diabetes who were taking oral medications (except acarbose) to maintain $\mathrm{HbA}_{1 \mathrm{c}}$ concentrations at $6.5 \%$ to $8 \%$.

Intervention: low-glycaemic index diet $(n=106)$ or highcereal fibre diet $(n=104)$ for 6 months. The low-glycaemic diet consisted of low-glycaemic index breads and cereals, pasta, parboiled rice, beans, peas, lentils, nuts, and temperate fruits. The high-cereal fibre diet consisted of whole grain and whole wheat breads and cereals, brown rice, potatoes with skins, and tropical fruits. All participants were advised to avoid certain foods, including pancakes, muffins, donuts, white buns, cookies, cakes, fries, and chips.

Outcomes: included changes in $\mathrm{HbA}_{1 \mathrm{c}}$, fasting glucose, cholesterol, and triglyceride concentrations; body weight; and blood pressure (BP).
Follow-up period: 6 months.

Patient follow-up: $80 \%$ (100\% in primary intention-to-treat analysis).

\section{MAIN RESULTS}

The low-glycaemic diet decreased $\mathrm{HbA}_{1 \mathrm{c}}$ and fasting glucose concentrations and increased high-density lipoprotein cholesterol concentrations compared with the high-fibre diet (table). Groups did not differ for changes in triglyceride concentrations, body weight, or BP.

\section{CONCLUSION}

6-month treatment with a low-glycaemic index diet reduced $\mathrm{HbA}_{1 \mathrm{c}}$ concentrations more than a high-cereal fibre diet in patients with type 2 diabetes.

*See glossary.

\section{ABSTRACTED FROM}

Jenkins DJ, Kendall CW, McKeown-Eyssen G, et al. Effect of a low-glycemic index or a high-cereal fiber diet on type 2 diabetes: a randomized trial. JAMA 2008;300:2742-53.

Correspondence to: Dr D J Jenkins, University of Toronto, Toronto, Ontario, Canada; cyril.kendall@utoronto.ca

Source of funding: Canadian Institutes of Health Research.

- Clinical impact ratings: GP/FP/Primary care 6/7; Endocrine 6/7; IM/Ambulatory care $5 / 7$

Low-glycaemic index diet $v$ high-cereal fibre diet in type 2 diabetes*

\begin{tabular}{lcll}
\hline & \multicolumn{2}{c}{ Mean change from baseline } & \multicolumn{1}{c}{ At $\mathbf{6}$ months } \\
\cline { 2 - 3 } Outcomes & Low-glycaemic diet & High-fibre diet & Difference in change between groups (95\% Cl) \\
\hline Haemoglobin $\mathrm{A}_{\mathrm{c}}(\%)$ & -0.50 & -0.18 & $-0.33(-0.48$ to -0.17$)$ \\
Fasting glucose $(\mathrm{mg} / \mathrm{dll})$ & -11 & -4.4 & $-6.8(-13$ to -0.6$)$ \\
High-density lipoprotein cholesterol $(\mathrm{mg} / \mathrm{d}) \dagger$ & 1.7 & -0.2 & $1.9(1.8$ to 2.0$)$ \\
\hline
\end{tabular}

${ }^{*} \mathrm{Cl}$ defined in glossary.

$\dagger$ Difference in change between groups and $\mathrm{Cl}$ calculated from data in article.

linicians generally accept the idea of glycaemic indexing. What remains unresolved is the question posed by Jenkins et al: what is the effect of a low-glycaemic diet on glucose control in patients with type 2 diabetes? In the carefully managed 6-month study by Jenkins et al, the $\mathrm{HbA}_{1 \mathrm{c}}$ concentration dropped $0.5 \%$ in the low-glycaemic index group compared with a significantly smaller drop $(0.18 \%)$ in the high-cereal fibre diet group. The study design assures that the study outcome probably reflects the comparative effect of the lowglycaemic diet, with some concerns.

The first concern in this otherwise useful study refers to researchers' decision to ask both groups to eliminate foods with high glycaemic indices (including pancakes, muffins, french fries, and chips). If the intent of the study was to measure the comparative effect of a low-glycaemic diet, it would have been more useful to allow the highcereal fibre group to not eliminate high-glycaemic index foods. This decision reduced the dietary difference between groups in terms of glycaemic index and may have led to an underestimation of the treatment effect.

The second concern arises from the far greater fibre intake in the low-glycaemic group compared with the high-fibre group. Also, in the diet design of the study, the low-glycaemic diet group was instructed to eat "temperate" fruits only whereas the high-cereal fibre diet group was advised to eat "tropical" fruits only. No explanation was offered for this instruction. As a result, whether the effect of the low-glycaemic diet is attributable to the greater use of low-glycaemic foods or, alternatively, to increased fibre intake, or to the consumption of specific fruits remains unclear.

These concerns should not prevent the reader from concluding that fibre-rich low-glycaemic diets can improve glycaemic control in patients with type 2 diabetes. Whether it is the amount of fibre alone that makes a difference in glucose control, or some unidentified property of low-glycaemic index foods, it seems clear that the net benefit in metabolic control is reasonably certain.

\section{Eugene C Corbett, Jr, MD \\ University of Virginia}

Charlottesville, Virginia, USA 